The Geneva Papers on Risk and Insurance, 17 (No. 64, July 1992), 386-392

\title{
Greenhouse Effects on Natural Catastrophes and Insurance
}

\author{
by Gerhard A. Berz*
}

\section{Summary}

In the last few decades, the international insurance industry has been confronted with a drastic increase in the frequency of great natural disasters. A comparison of the $60 \mathrm{~s}$ with the $80 \mathrm{~s}$ on the basis of fairly comprehensive loss data shows an increase of total economic losses (adjusted for inflation) by a factor of 3.1 and of total insured losses by a factor of as much as 4.8. The economic and record insured losses in 1990 of some US $\$ 25$ and 10 billion respectively are further confirmations of this significant trend.

The trend is primarily attributable to the continuing steady growth of the world population and the increasing concentration of people and economic values in urban areas. An additional factor is the global migration of populations and industries into areas like the coastal regions, which are particularly exposed to natural hazards. The natural hazards themselves, on the other hand, have not yet shown any significant increase.

In addition to the problems the insurance industry has with regard to pricing, capacity and loss reserves, the assessment of insured liabilities, preventive planning and the proper adjustment of catastrophe losses are gaining importance.

The present problems will be dramatically aggravated if the greenhouse predictions come true. The increased intensity of all convective processes in the atmosphere will force up the frequency and severity of tropical cyclones, tornadoes, hailstorms, floods and storm surges in many parts of the world with serious consequences for all types of property insurance. Rates will have to be raised and in certain coastal areas insurance coverage will only be available after considerable restrictions have been imposed, e.g. significant deductibles and low liability or loss limits.

In areas of high insurance density the loss potential of individual catastrophes can reach a level where the national and international insurance industries run into serious capacity problems. One possible solution is the involvement of governments in catastrophe pools or funds, as is the case in several countries.

\footnotetext{
* Munich Reinsurance Company, Munich, Germany. Paper presented at the Fourth International Conference on Strategic Planning and Issues in Insurance in London, on October 28 to 30, 1991.
} 
Recent case studies show the overproportionally high participation of reinsurers in extreme disaster losses and the need for more risk transparency if the insurance industry is to fulfil its obligations in an increasingly hostile environment.

\section{Increase in the scope and frequency of major natural catastrophes}

The scope and frequency of loss incurred by natural catastrophes have experienced a drastic increase worldwide over the past decades. This realization results from the statistical analysis of the comprehensive loss data that the "Natural Hazards Research Group" of Munich $\mathrm{Re}$ has been continuously collecting over the last 30 years and has evaluated in connection with the preparation of its "World Map of Natural Hazard", which is now in its second edition. Each month brings data on 20 to 50 new loss events. Fortunately, however, only a few of these have to be added to the list of great natural disasters, that is, only those involving damage that considerably exceeds what the country or region affected can handle itself and for which the country requires substantial national or international aid. This is generally the case if the number of casualties runs into the hundreds or thousands, if tens or hundreds of thousands of people are rendered homeless and if the total economic loss is in the region of US $\$ 100$ million.

Fairly comprehensive data exist on these great disasters, even those that occurred farther back in the past. They numbered only 14 in the 1960s, and 70 in the 1980s, which means that they increased within three decades by a factor of 5 . The trend is also very clear when we consider the total economic loss, which, adjusted for inflation, increased during the same period from an annual average of US $\$ 3.7$ billion per year to US $\$ 11.4$ billion, i. e. by a factor of 3.1. The insured losses increased by an even larger factor of 4.8 . At the present time, the insurance industry worldwide must count on an annual average burden from natural catastrophes of US $\$ 5$ billion. The fact that the total of insured losses in certain years can by far exceed these amounts was proved only in 1990 by the winter storms in Europe, which amounted to approximately US $\$ 10$ billion. At the same time, this must certainly also be taken as an indication for the fact that catastrophic losses are continuing to climb sharply.

This upward trend is of course mainly attributable to the persisting unbridled growth of the world population paralleled by a general improvement in living standards and the increasing concentration of people and economic values in urban areas. An UN prognosis states that the number of cities with populations in the millions will increase from 200 to 400 within 20 years and, in the same time period, cities with populations in the tens of millions from 10 to 25 . An additional factor is the global migration of populations into coastal regions, which are generally more highly exposed to natural catastrophes. And, finally, there is industry, which, to some extent following the movement of the people and usually seeking new resources or transport routes, is nowadays venturing increasingly into regions that are subject to elemental perils, without always making proper allowance for this by implementing appropriately safe technologies. Examples of this range from the hotels concentrated along the hurricane-exposed coasts of Florida and the Caribbean to the offshore industry operating in the North Sea and in the Arctic, or to nuclear power plants located in extremely hazardous earthquake-prone areas or even on top of active geological faults. In addition to this, the earthquake of October 1989 in California showed how extremely vulnerable highly-developed regions are today to any disruption of the infrastructure, especially communication networks. 
At the same time, the density of insured natural hazards in certain geographic areas has greatly increased, and of course particularly so in highly exposed countries. This not only applies to California, a region exposed to earthquakes, where approximately every third house is insured against earthquake today in comparison with a few years ago where it was only every 14th house. In the Federal Republic of Germany as well, in the time period since 1976, the year of the "Capella" gale, for example, the number of homeowner's policies with windstorm coverage has increased by $65 \%$; furthermore, during the same period, the repair-cost index for residential buildings increased by $70 \%$. The rapid spread of all-risks and loss of profits covers is also considerably increasing the loss burdens to insurers from natural catastrophes.

\section{Repercussions from the greenhouse effect}

Natural hazards themselves have not yet shown any significant increase, although today there are more and more alarming factors indicative of the gradual but noticeable increase in the worldwide temperatures. Let us consider for example that the areas of the Pacific with a water temperature of over $27^{\circ} \mathrm{C}$ - which is an important precondition for the development of tropical storms - have increased in the last 20 years by roughly $1 / 6$ th. The extreme intensity of the super-hurricanes "Gilbert" in 1988 and "Hugo" in 1989, as well as the extraordinary series of winter gales last year, can be regarded as a further indication that the warming of the global climate is gradually beginning to have some noticeable effects.

In global terms 1990 was the warmest year, at least since worldwide meteorological measurements started some 130 years ago. Another five years of the last decade also rank higher than all values measured so far in terms of mean global temperature. Never before, at least in the last 7 centuries, has there been the same succession of mild and dry winters in Central Europe as in the years from 1987 to 1990.

The artificial increase in global temperatures is caused primarily by the continuous release of carbon dioxide, methane, nitrous oxide and chlorofluorocarbons used by mankind, which adds to the natural greenhouse effect of the atmosphere. While this natural effect heats the earth's surface by some $30^{\circ}$, with water vapour as its main contributing factor, we must expect an increase in global temperatures of between $2^{\circ}$ and $5^{\circ}$ from artificial causes by the middle of the next century. This would be the highest mean temperature since the beginning of the ice age roughly 2.5 million years ago.

A similarly wide range is to be found among the forecasts of the rise in the sea level, which has so far amounted to about $10 \mathrm{~cm}$. The most likely prognosis is that the mean sea level will rise by some $30 \mathrm{~cm}$ by the middle of the next century; it is quite possible, however, that it will rise by as much as 1 metre. Most of this increase is attributable to the thermal expansion of the water in the oceans and melting ice, which is already taking on dramatic proportions in some regions, notably in the Alps.

Assuming that all the predicted effects become reality, we will be faced with consequences like the following:

- The number and intensity of natural meteorological catastrophes will grow, because the atmospheric heat engine is operating at a faster speed than ever before. The result is increased circulation in the atmosphere and the oceans. Tropical cyclones are becoming more frequent and more severe, and now extend their paths towards the 
moderate latitudes (e.g. towards Western Europe and California). There is also more water vapour in the atmosphere, generally causing more precipitation and flooding, more thunderstorms, hailstorms and tornadoes.

- All over the world, the risk of storm surges along many densely populated coastlines will increase. Probably the situation is most extreme in Bangla Desh, but the Netherlands as well as other coastal areas in the southern regions of the North Sea, including the estuaries of the River Elbe and River Thames, are also becoming more exposed. Billions of dollars will be needed to protect the coastlines.

- Agricultural and forestry conditions will change. While they will presumably become better in some moderate and sub-polar regions - not only because of the warmer and wetter climate, but also due to the larger amount of carbon dioxide in the air - other regions will be confronted with more and more severe droughts. This applies particularly to regions along the dry sub-tropical zone, such as the entire Mediterranean, the Midwest USA and the south of the USSR. It would appear to be only a matter of time until these regions run into social and political crises.

It is too early yet for a reliable forecast of regional effects. One thing is certain, however: the transition to a new stable climatic situation, if this occurs at all, will be accompanied by an exceptional frequency of anomalies which will generally give rise to catastrophes.

\section{Effects on the insurance industry and counter-measures}

The insurance industry will feel the effects of this in many different ways, most obviously in its agricultural policies but also in the other classes of property insurance providing windstorm, hail, lightning, flood, landslide and subsidence coverage.

The effects on motor, marine, life and health insurance are less obvious, although they certainly do exist. In the latter two cases, there may well be some consequences if the infamous ozone "hole" expands over more densely populated areas, as recently observed, and if the incidence of skin cancer increases as a result of "hard" ultraviolet radiation.

What should the insurance industry's response be to changed environmental conditions? This is a question that needs to be faced most urgently by the reinsurers because the individual losses resulting from any major natural catastrophe tend to accumulate in their accounts as a result of their international treaty commitments. In order to realize how large a reinsurer's share of the losses caused by a major natural catastrophe can be, let us just recall the 1985 Mexico City earthquake, in which only $2 \%$ of the total insured loss of US $\$ 275$ million had to be paid by the local market, leaving the prodigious "remainder" of $98 \%$ to be borne by the foreign reinsurers. The situation was much the same in the aftermath of hurricane "Gilbert" in Jamaica in 1988. And, as revealed in a recent analysis, even in an insurance market as strong as that of the USA more than half of the total loss of roughly US $\$ 14$ billion caused by a hypothetical hurricane would have to be paid by domestic and foreign reinsurance companies. Only by ensuring a worldwide geographical spread of their liabilities can international reinsurers bear such extreme burdens. It is reinsurance that makes it at all possible for direct insurers to offer insurance against natural catastrophes. Such insurance coverage would be unthinkable on a strictly national basis. 
Insurers and reinsurers basically have two options for overcoming the increased loss potential from natural catastrophes or, more generally, a change in risk conditions: either to adjust their own attitudes, or to prevent or limit the consequences.

The latter would imply, for example, the "ultima ratio" of partially or entirely excluding certain hazards from insurance coverage, or, alternatively, either requiring the policyholder to make a substantial contribution to the cost of losses through deductibles or other methods of coinsurance, or limiting the insurer's liability to a certain agreed maximum. It is, however, a neverending challenge for the insurance industry, and especially for the industry's reinsurers, to guarantee by means of the appropriate conditions that virtually every risk remains insurable.

The insurer cannot provide unlimited capacity blindly. Like every private enterprise, an insurance company must ensure that the capital it makes available is suitably protected. Our "product" is basically a promise to assume liability for the future. The consequences of any changes taking place between the time that liability is assumed and the end of the policy period therefore have to be borne by the insurer and reinsurer. Our duty as conscientious businessmen to exercise the necessary care means that we must constantly check and evaluate the extent of our obligations. In the first place, a reinsurer must know what liabilities he has assumed for each type of hazard in each region that is exposed to that particular hazard. On this basis he can calculate the size of his potential loss, that is, the maximum loss he will have to bear as a result of the most extreme event that is likely to affect each of the zones and classes of insurance in which he operates.

To this end the concept of accumulation control was developed. This enables us to gain a general picture of the current status of our liabilities, broken down into the relevant accumulation zones. These zones are defined by scientists and underwriters in such a way that they allow a simulation of various catastrophe scenarios for each market with sufficient exactitude in a way that will not create too much administrative work. Usually this is done by using statistical methods to calculate the geographical extent and intensity distribution of hypothetical extreme events, that is, major earthquakes, storms, etc., as a function of various probabilities of occurrence. The liabilities existing in the zones involved are multiplied by the loss ratios that correspond to the calculated intensity and probability of occurrence in each liability category. The resulting loss amounts per zone are then added together to obtain the total loss potential for each catastrophe scenario.

Both the individual and the accumulative risk analyses can be carried out by means of appropriate PC programmes. For example, using an earthquake programme based on comprehensive seismological data and worldwide claims statistics, the loss exposure of an entire portfolio is calculated as a function of the probability of occurrence. Such an analysis can create a basis for making very important decisions of business policy regarding necessary reinsurance or retrocession protection and adequate catastrophe reserves.

The most "costly" catastrophe scenarios today are still repetitions of the earthquakes of 1906 in San Francisco and 1923 in Tokyo, which would cause losses far exceeding one hundred billion US dollars and would burden the insurance industry with claims worth tens of billions, by cautious estimate. As regards insured losses, similar sums would mount up as a result of a "hundred-year" windstorm in the USA or Central Europe. That these figures are not mere fabrications was proved by the 1987 October gale in Britain and France, the 1989 hurricane "Hugo" and the 1990 winter gales in Europe, which cost the insurance industry new record sums of US $\$ 3.1,4.5$ and some 10 billion. 
In view of these sums, if both the frequency and the intensity of catastrophic events continue to increase, the question may arise as to what the insurance industry can do in order to avoid to whatever extent possible undesirable limitations of liability. How long the insurance industry will be able to continue fulfilling its function depends on the speed and agility with which it can adjust to a changing environment.

This can be achieved by applying loss reduction measures, like promoting windstormand earthquake-proof building design or by introducing adequate deductibles and, most important, by charging premiums that are truly commensurate with the risk. Unfortunately, this is still today exclusively based on loss experience of the past and, under competitive pressure, corners are often even cut further.

It is becoming more and more important for insurance markets exposed to catastrophe to create an organizational structure in anticipation of problems which predictably arise in the wake of a natural catastrophe for assessment and adjustment of what might be millions of individual losses incurred simultaneously. Authorities are also challenged to set more stringent construction regulations and limit land use in highly exposed regions. Industry can contribute significantly by applying more strict criteria in its choice of a location for particularly vulnerable or hazardous facilities.

Reference should also be made in this connection to the "International Decade for Natural Disaster Reduction", as proposed by the United Nations for the last decade of this century to combat the increasing danger of natural disasters to mankind. This programme is of great significance to the insurance industry, as it includes the following topics:

- mapping of hazard zones

- assessment of loss potentials resulting from different catastrophe scenarios

- land use regulations / restrictions

- standardization of building codes

- standardization of loss information

- forecast and warning services

- public information / awareness / motivation.

The insurance industry should, therefore, become a major partner in this programme. It can, at the same time, expect significant long-term benefits from the programme on a national and global scale.

If the annual fluctutations in results increase as a consequence of more and more frequent and greater catastrophes, it will also become necessary to set aside more funds for catastrophe reserves. The issue here is to convince tax authorities that premiums paid for the coverage of natural catastrophes cannot be considered as "earned" premiums at the end of the year, but rather only after very long risk periods.

In summary it can be said that by properly applying all instruments of insurance and working together with science, industry and authorities, the repercussions of the increase of catastrophic events need not necessarily be negative for the insurance industry and there is every reason to be optimistic that these risks will remain insurable for insurance clients worldwide. 
Great Natural Disasters, 1960-1990

Frequency and Loss Extent

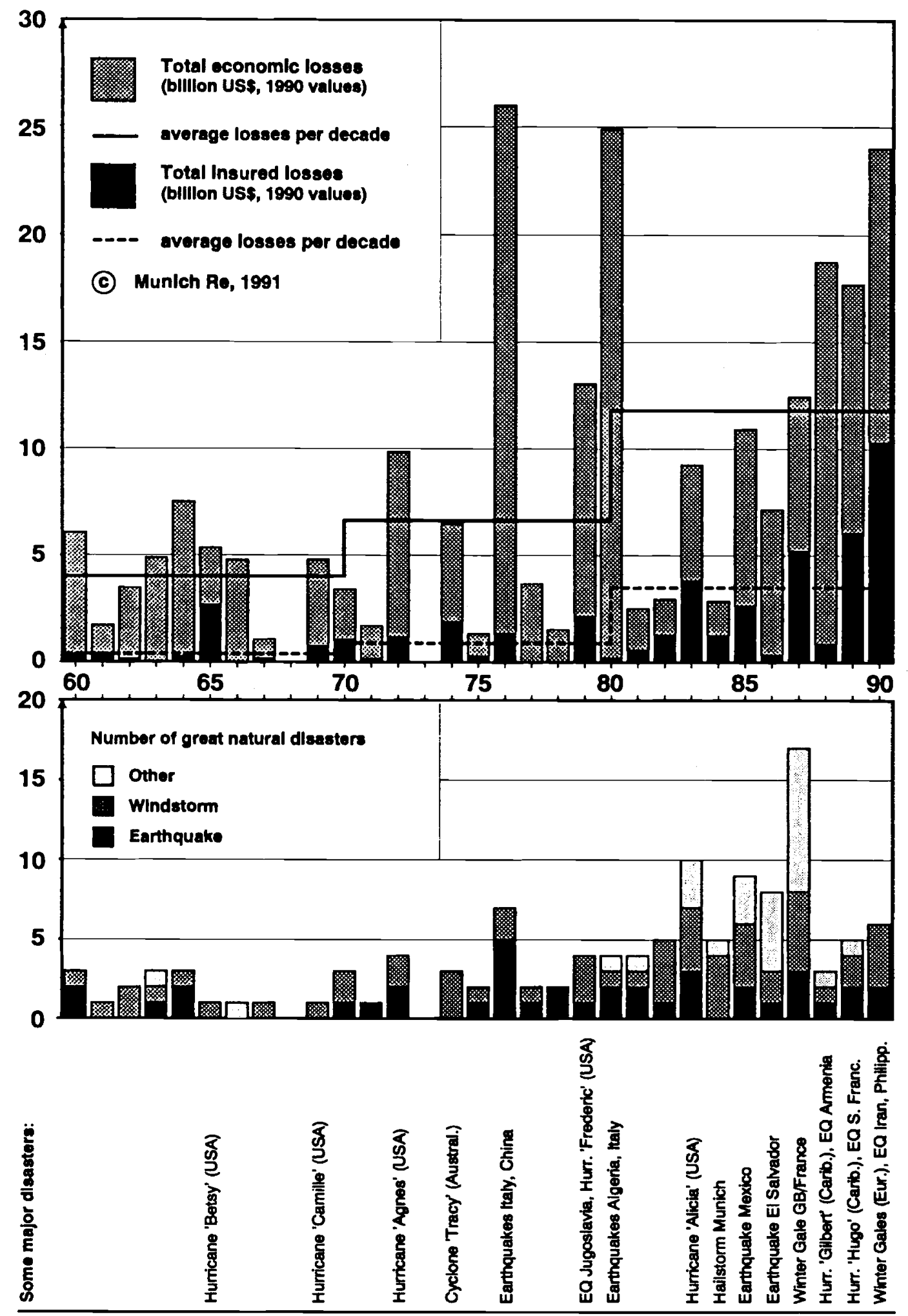

